\title{
Riverbed methanotrophy sustained by high carbon conversion efficiency
}

Mark Trimmer, Felicity C Shelley, Kevin J Purdy, Susanna T Maanoja, Panagiota-Myrsini Chronopoulou and Jonathan Grey

The ISME Journal (2015) 9, 2328; doi:10.1038/ismej.2015.173

Correction to: The ISME Journal (2015) 9, 2304-2314; doi:10.1038/ismej.2015.98

Since the publication of this paper, the author has discovered the incorrect spelling of an author's name. 'Grey Jonathan' should be 'Jonathan Grey'.
The publisher would like to apologize for any inconvenience this may have caused.

\section{Making pathogens sociable: the emergence of high relatedness through limited host invasibility}

Edwin van Leeuwen, Sarah O'Neill, Andrew Matthews and Ben Raymond

The ISME Journal (2015) 9, 2328; doi:10.1038/ismej.2015.174

Correction to: The ISME Journal (2015) 9, 2315-2323; doi: 10.1038/ismej.2015.111

After the publication of this paper, the authors noticed an error in the title. The correct title is
'Making pathogens sociable: the emergence of high relatedness through limited host invasibility'.

The publisher would like to apologise for any inconvenience this may have caused. 